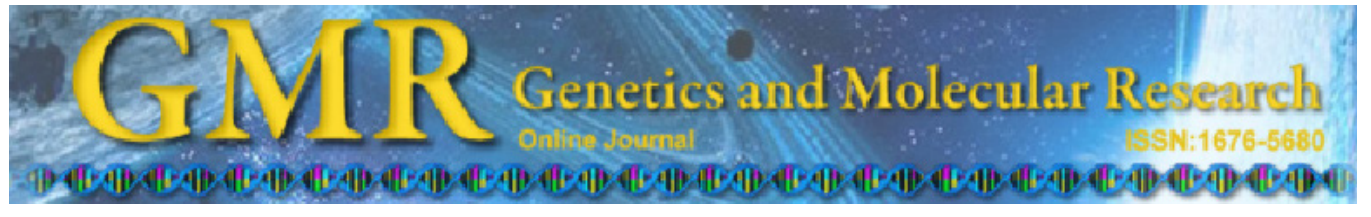

\title{
Increased androgen receptor messenger RNA in frontal-parietal hair follicles of women with androgenetic alopecia
}

\author{
F. Richeti ${ }^{1}$, C. Kochi ${ }^{1}$, M.N. Rocha ${ }^{1}$, C. Sant'Anna Corrêa ${ }^{1}$, R. Lazzarini ${ }^{2}$, \\ R.M. Guazzelli ${ }^{3}$, R.F. Mendonça ${ }^{3}$, M.R. Melo ${ }^{1}$ and C.A. Longui ${ }^{1}$ \\ ${ }^{1}$ Laboratório de Medicina Molecular, Departamento de Ciências Fisiológicas, \\ Faculdade de Ciências Médicas da Santa Casa de São Paulo, São Paulo, \\ SP, Brasil \\ ${ }^{2}$ Clínica de Dermatologia, Irmandade Santa Casa de Misericórdia de São Paulo, \\ São Paulo, SP, Brasil \\ ${ }^{3}$ Graduandos do Curso de Medicina, \\ Faculdade de Ciências Médicas da Santa Casa de São Paulo, São Paulo, \\ SP, Brasil
}

Corresponding author: C.A. Longui

E-mail: carloslongui@msn.com

Genet. Mol. Res. 12 (2): 1834-1840 (2013)

Received December 15, 2011

Accepted November 22, 2012

Published February 28, 2013

DOI http://dx.doi.org/10.4238/2013.February.28.19

ABSTRACT. Normal testosterone levels are frequently observed in
women with androgenetic alopecia (AGA), suggesting the involvement
of androgen sensitivity in this condition. Androgen sensitivity is related
to androgen receptor (AR) messenger RNA (mRNA) production in
hair follicles and is negatively related to the number of CAG repeats
present in exon 1 of the AR gene. The aim of this study was to compare
AR expression in AGA women with normal controls and to correlate
this expression with the number of CAG repeats. Hair follicles were
obtained from 27 women with AGA and 21 controls for AR gene
expression analysis. AR expression was evaluated through AR mRNA
quantification using real-time polymerase chain reaction and the number
of CAG repeats in the AR gene was determined in complementary DNA 
samples obtained from hair follicles and analyzed with the Gene Scan software. AR mRNA in the frontal-parietal region was significantly higher than in the occipital region of AGA patients (paired $t$-test, $\mathrm{P}=$ 0.046). No significant difference was identified in controls $(P=0.67)$. Both regions in the same individual showed a significant positive correlation in AGA patients $(\mathrm{r}=0.77 ; \mathrm{P}<0.05)$ and in controls $(\mathrm{r}=0.91$; $\mathrm{P}<0.05)$. A negative correlation was identified between AR expression and the number of CAG repeats only in AGA patients $(\mathrm{r}=0.510 ; \mathrm{P}=$ 0.013). The identification of elevated AR mRNA quantitation in hair follicles is a useful tool for identifying potentially abnormal androgen sensitivity in AGA patients.

Key words: Androgenetic alopecia; Androgen receptor; CAG repeats

\section{INTRODUCTION}

Androgenetic alopecia (AGA) is caused by the vellus transformation of scalp hair, which corresponds to hair follicle miniaturization through repeated hair cycles with shortened anagen phase, particularly in the frontal and parietal regions (Uno et al., 1967; Inui et al., 2009). Using clinical evidence, Hamilton (1942) was the first to demonstrate that this process is mediated mainly by androgens. Androgens are involved in several functions in human skin, including sebaceous gland growth and differentiation, hair growth, epidermal barrier homeostasis, and wound healing, through a multi-step signaling pathway (Zouboulis and Degitz, 2004). The absence of correlation between AGA and serum testosterone suggests that free testosterone and bioavailable testosterone are involved in the pathogenesis of AGA through intracellular signaling of hair follicle target cells (Inui and Itami, 2001). The action of androgens is mediated by specific nuclear androgen receptors (ARs) encoded by a gene located on the X chromosome, which functions as a hormone-inducible transcription factor. In hair follicles, ARs are not located in epithelial cells but in dermal papilla, indicating that the latter are the main targets for androgen in hair follicles. Subtle modulation of AR transcriptional activity has been identified in a polyglutamine stretch of variable length within the $\mathrm{N}$-terminal domain of the receptor. This stretch is encoded by a variable number of CAG repeats in exon 1 (Zitzmann and Nieschlag, 2003).

Compared with controls, men with AGA present significantly shorter CAG repeat residues (Sawaya and Shalita, 1998; Ellis et al., 2001). In the present study, we analyzed AR gene expression in women with AGA by measuring AR messenger RNA (mRNA) concentration in hair follicles and its correlation with the number of CAG repeats encoded by exon 1 of the AR gene.

\section{MATERIAL AND METHODS}

Twenty-seven women with AGA [median (range) age of 47.3 (23-75) years] were examined and classified according to Ludwig scoring as alopecia grades I, II, or III. These patients were compared with 21 female controls aged 21.3 (18-30) years. Patients with clinical virilization or who had undergone therapy with drugs that could influence steroidogenesis 
or androgen action, such as flutamide, espironolactone, cyproterone, drospirenone, finasteride, or oral contraceptives, during the preceding 3 months were excluded. The study protocol (\#322/08) was approved by the Institutional Ethics Committee, and all individuals signed a written consent before inclusion in the study.

Hair follicles from the frontal-parietal (FP) and occipital regions were obtained via manual traction (10 hair units from each region). The samples were smashed in storage solution (Trizol Reagent, Invitrogen, Carlsbad, CA, USA) to avoid RNA degradation and frozen at $-80^{\circ} \mathrm{C}$.

\section{Molecular analysis}

After fast defrosting, samples were placed in chloroform and centrifuged at $4{ }^{\circ} \mathrm{C}, 8000 \mathrm{~g}$, and for $15 \mathrm{~min}$. After centrifugation, the RNA contained in the aqueous phase was precipitated in $100 \%$ isopropanol followed by $85 \%$ ethanol. The RNA was then eluted in $40 \mu \mathrm{L}$ DNase- and RNase-free water, combined with $1 \mu \mathrm{L}$ RNase inhibitor (No. N8080234, Applied Biosystems), and stored at $-80^{\circ} \mathrm{C}$ for up to 2 weeks. RNA concentration was determined through spectrometry.

Complementary DNA (cDNA) was synthesized from $1 \mu \mathrm{g}$ total RNA using a reverse transcription reaction (TaqMan Reverse Transcription Reagents, Applied Biosystems). Realtime PCR quantitation of AR mRNA was performed and normalized with breakpoint cluster region (BCR) mRNA. AR sense and antisense primers were designed to include the transition of exons 4 and 5 of the AR gene (assay ID: Hs00171172_m1) and were based on the sequence provided by the National Center for Biotechnology Information (available at http://www.ncbi. nlm.nih.gov/nuccore/21322251). The AR probe FAM5NFQ-AGGCCTTGCCTGGCTTCCGC AACTT was used. For the BCR gene, we used sense primer: 5'-CCTTCGACGTCAATAACA AGGAT-3', antisense primer: 5'-CCTGCGATGGCGTTCAC-3', and probe 6-FAM-TCCATCT CGCTCATCATCACCGACA-TAMRA.

Real-time PCR was performed in an Applied Biosystems 7500 thermocycler (Applied Biosystems). The running conditions included an initial Taq Gold activation at $95^{\circ} \mathrm{C}$ for 10 min followed by 40 cycles of amplification of $15 \mathrm{~s}$ at $95^{\circ} \mathrm{C}$ and $90 \mathrm{~s}$ at $60^{\circ} \mathrm{C}$. In each PCR experiment, we used a standard curve composed of serial dilutions of cDNA obtained from ARexpressing normal prostate cells of cadaver origin. The $A R / B C R$ expression ratio represented the relative AR expression of each sample. The length of the CAG triplet repeats in exon 1 was determined in cDNA samples obtained from hair follicles. The exact number was established by comparing the size of the amplified fragment encoded by exon 1 with samples in which the number of CAG repeats was determined through sequencing analysis. The reaction included 5 pmol sense primer 6-FAM - 5'-GGG TAA GGG AAG TAG GTG GAA-3' (Invitrogen), and an unlabeled antisense primer: 5'-ACT GCG GCT GTG AAG GTT-3'. PCR also included 20 pmol unlabeled antisense primer, $200 \mu \mathrm{mol}$ of each deoxyribonucleotide triphosphate, $10 \mathrm{X}$ buffer, $0.5 \mathrm{U}$ Taq DNA polymerase (Biotools B\&M Labs S.A., Madrid, Spain), $50 \mathrm{mM} \mathrm{MgCl}$, and double-distilled $\mathrm{H}_{2} \mathrm{O}$ to obtain a final volume of $25 \mu \mathrm{L}$. PCR was performed using a GeneAmp PCR System 9700 thermocycler (Applied Biosystems) under the following conditions: denaturation step at $94^{\circ} \mathrm{C}$ for $3 \mathrm{~min}$ followed by 35 cycles of denaturation, annealing, and extension $\left(0.5,1\right.$, and $1 \mathrm{~min}$, respectively) and a final extension at $72^{\circ} \mathrm{C}$ for $1 \mathrm{~h}$. For each sample, the PCR product (fragment size of $395 \mathrm{bp}$ ) was then submitted to capillary gel electrophoresis in an ABI PRISM 310 automated analyzer (Applied Biosystems) under the following condi- 
tions: $60^{\circ} \mathrm{C}, 7-9 \mathrm{kV}$ for $28 \mathrm{~min}$. The results were analyzed using the GeneScan software, which determined the relative size of the amplified fragment that depends on the number of CAG repeats present in exon 1 of the AR gene.

\section{Statistical analyses}

Statistical analyses were performed using SPSS for the Windows software, version 10.0.1 (SPSS Inc., Chicago, IL, USA). The Student $t$-test was used to compare variables between AGA patients and controls; a paired $t$-test was used to compare the AR mRNA levels from the FP and occipital regions of the same patient. Linear regression was used to evaluate the correlation between AR mRNA level and number of CAG repeats.

\section{RESULTS}

The relative amounts of AR mRNA were determined in AGA patients, both in the FP [mean \pm standard deviation $(\mathrm{SD})=0.005 \pm 0.006)$ and occipital $(0.004 \pm 0.004)$ regions. In women with AGA, the amount of AR mRNA in the FP region was significantly higher than that in the occipital region (paired $t$-test, $\mathrm{P}=0.046$ ). No significant difference was identified in controls $(\mathrm{P}=0.67)$ when the FP $(0.007 \pm 0.007)$ and occipital $(0.004 \pm 0.005)$ regions were compared.

When the amounts of AR mRNA from the 2 regions (FP and occipital) of the same individual were compared (Figure 1), a significant positive correlation was identified both in AGA patients $(\mathrm{r}=0.77 ; \mathrm{P}<0.05)$ and in controls $(\mathrm{r}=0.91 ; \mathrm{P}<0.05)$.
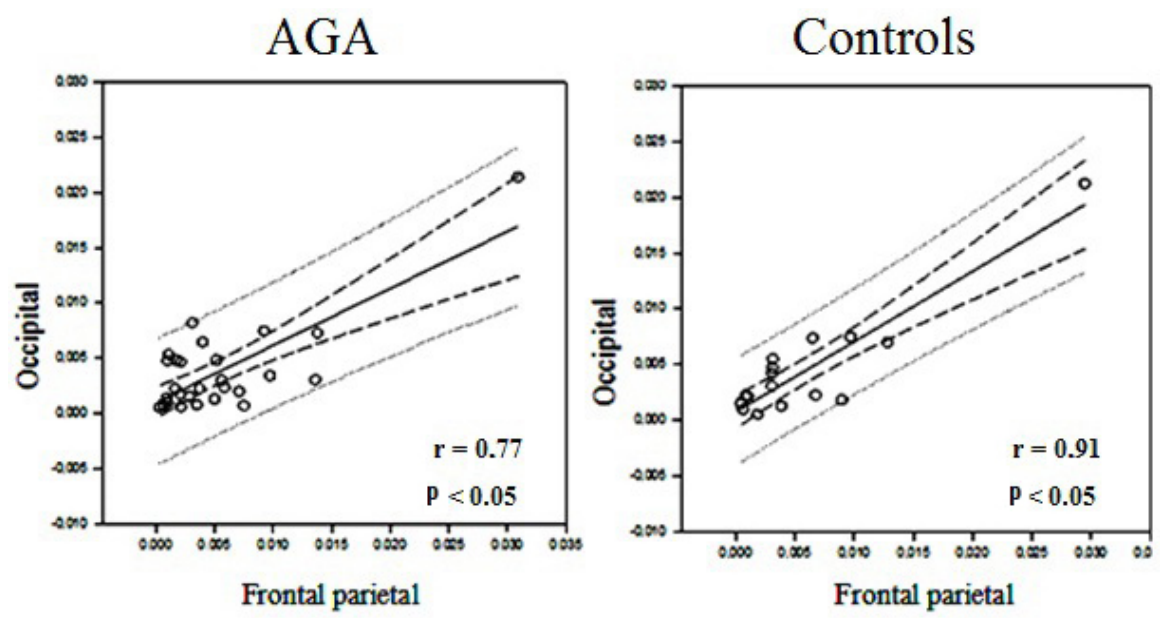

Figure 1. Correlation between the amounts of androgen receptor mRNA from the two different regions of hair follicles (frontal-temporal and occipital) of the same individual. AGA = androgenetic alopecia.

The number of CAG repeats is a polymorphic trait. By determining the number of CAG repeats from the hair follicle mRNA, we were able to determine the predominant allele expression. We identified the expected biallelic expression in only 13 of 24 AGA patients and in 7 of 21 controls, from which we obtained adequate samples for this analysis (Figure 2). 


\section{(A) Genotyping hair follicle cDNA monoallelic expression}

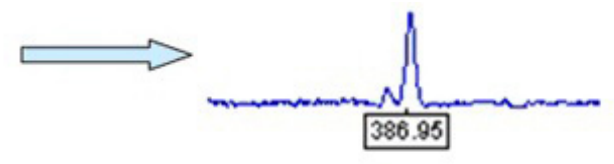

(B) Genotyping hair follicle cDNA biallelic expression

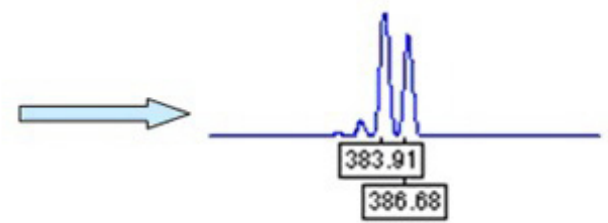

Figure 2. Example of genotyping determined in cDNA obtained from hair follicles showing monoallelic (A) and biallelic expression (B).

In the AGA group, the mean numbers of CAG repeats in shorter and longer alleles were 21 and 24, respectively. In the control group, 22 and 24 repeats were detected in the shorter and longer alleles, respectively. No significant difference was identified between the groups $(\mathrm{P}=0.32)$, only a trend toward reduced size of the shorter allele in AGA patients when compared with controls $(\mathrm{P}=0.078)$. A significant negative correlation observed only in AGA patients when the amount of AR mRNA was compared with the mean number of CAG repeats (Figure 3).

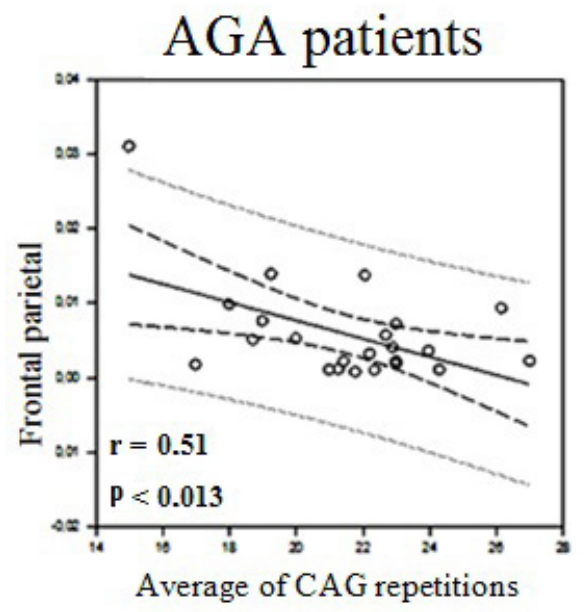

Figure 3. Correlation between the amounts of androgen receptor (AR) mRNA from hair follicles and the number of CAG repeats encoded by the exon 1 of the AR gene. AGA = androgenetic alopecia.

\section{DISCUSSION}

Previous studies have demonstrated the role of androgens in AGA, but in several cases, androgen concentration has been normal unrelated to the severity of AGA. Therefore, the predominant action of androgens through ARs suggests the potential involvement of AR expression in hair follicles in the pathogenetic development of alopecia (Inui and Itami, 2001). 
Animal studies have demonstrated that androgens are responsible for growth delay in new hair follicles, acting through the AR pathway (Crabtree et al., 2010). In the present study, the AGA group displayed increased AR expression in the FP region not observed in normal controls, confirming the role of androgen hypersensitivity in this region. Other studies using hormone-binding assays and real-time PCR methodology have also demonstrated that AR expression is significantly higher in bald dermal papilla cells than in non-bald cells, indicating that enhanced AR expression can increase sensitivity to androgens in the dermal papilla cells of AGA patients (Nakanishi et al., 1996).

The exact mechanism through which the androgen-AR complex induces or maintains AGA is still not completely understood. A possible interference in the Wnt signaling pathway has been proposed. This pathway is well recognized in the control of hair growth through the activation of $\beta$-catenin. Activated ARs seem to interact with $\beta$-catenin, determining the inhibition of Wnt (Andl et al., 2002; Van Mater et al., 2003).

In this study, we also evaluated the correlation between the amount of AR mRNA expressed in hair follicles and the number of CAG repeats encoded by exon 1 of the AR gene. Shorter alleles composed of a reduced number of CAG repeats usually presented higher expression rates and an increased expression of the AR protein. The expected negative correlation between increased AR expression and shorter CAG repeats was observed only in the FP region of AGA patients and not in controls.

Conversely, no correlation exists between the number of CAG repeats and responsiveness to the anti-androgen finasteride (Yamazaki et al., 2011), suggesting that other modulatory mechanisms of AR expression are likely involved in AGA. We found increased monoallelic expression of AR mRNA in the hair follicles of both AGA patients (46\%) and controls $(66 \%)$, much higher than the 10-15\% homozygosis expected at the AR gene locus (La Spada, 1997).

To evaluate this pattern of monoallelic or biallelic expression more thoroughly, we obtained blood samples from 5 women in the control group with monoallelic expression patterns at the follicle level. The results of peripheral blood mononuclear cell DNA genotyping in these samples showed that 4 of the 5 women were heterozygous for CAG repeats, suggesting that the methylation pattern is in fact predominant in only one allele at the follicle level.

Future studies should investigate the relevance of this skewed methylation pattern and other controlling mechanisms specific to AR expression in hair follicles and their influence on the predominance of monoallelic expression. Direct AR mRNA quantitation in hair follicles is a useful method for the identification of potential androgen sensitivity in this region. It should be combined with the determination of the number of CAG repeats and the identification of predominant allele expression to improve the recognition of androgen sensitivity.

\section{ACKNOWLEDGMENTS}

Research supported by Conselho Nacional de Desenvolvimento Científico e Tecnológico (\#471278/2009-2).

\section{REFERENCES}

Andl T, Reddy ST, Gaddapara T and Millar SE (2002). WNT signals are required for the initiation of hair follicle development. Dev. Cell 2: 643-653.

Crabtree JS, Kilbourne EJ, Peano BJ, Chippari S, et al. (2010). A mouse model of androgenetic alopecia. Endocrinology 
151: 2373-2380.

Ellis JA, Stebbing M and Harrap SB (2001). Polymorphism of the androgen receptor gene is associated with male pattern baldness. J. Invest. Dermatol. 116: 452-455.

Hamilton JB (1942). Male hormone stimulation is prerequisite and an incitant in common baldness. Am. J. Anat. 71: 451-480.

Inui S and Itami S (2011). Molecular basis of androgenetic alopecia: From androgen to paracrine mediators through dermal papilla. J. Dermatol. Sci. 61: 1-6.

Inui S, Nakajima T and Itami S (2009). Scalp dermoscopy of androgenetic alopecia in Asian people. J. Dermatol. 36 : $82-85$.

La Spada AR (1997). Trinucleotide repeat instability: genetic features and molecular mechanisms. Brain Pathol. 7 : 943-963.

Nakanishi S, Adachi IS and Takayasu KS (1996). Expression of Androgen Receptor, Type I and Type II 5a-Reductase in Human Dermal Papilla Cells. In: Hair Research for the Next Millennium (Van Neste DJJ and Randall VA, eds.). Elsevier Science, New York, 333-337.

Sawaya ME and Shalita AR (1998). Androgen receptor polymorphisms (CAG repeat lengths) in androgenetic alopecia, hirsutism, and acne. J. Cutan. Med. Surg. 3: 9-15.

Uno H, Allegra F and Adachi K (1967). Studies of common baldness of the stumptailed macaque: 1. Distribution of the hair follicles. J. Invest. Dermatol. 49: 288-296.

Van Mater D, Kolligs FT, Dlugosz AA and Fearon ER (2003). Transient activation of $\beta$-catenin signaling in cutaneous keratinocytes is sufficient to trigger the active growth phase of the hair cycle in mice. Genes Dev. 17: 1219-1224.

Yamazaki M, Sato A, Toyoshima KE, Kojima Y, et al. (2011). Polymorphic CAG repeat numbers in the androgen receptor gene of female pattern hair loss patients. J. Dermatol. 38: 680-684.

Zitzmann M and Nieschlag E (2003). The CAG repeat polymorphism within the androgen receptor gene and maleness. Int. J. Androl. 26: 76-83.

Zouboulis CC and Degitz K (2004). Androgen action on human skin - from basic research to clinical significance. Exp. Dermatol. 13 (Suppl 4): 5-10. 